\title{
Rancang Bangun Sistem Informasi Pariwisata Kecamatan Muaragembong Berbasis Web
}

\author{
Dewi Yuliandari ${ }^{[1]}$, Oryza Gilang $\mathrm{H}^{[2]}$, Feri Prasetyo ${ }^{[3]}$ \\ AMIK BSI Bekasi, Jl. Cut Mutiah No. 88, Bekasi ${ }^{[1],[3]}$ \\ STMIK Nusa Mandiri, Jl. Damai No. 8, Warung Jati Barat, Ps. Minggu, Kota Jakarta Selatan ${ }^{[2]}$ \\ Dewi.dwy@ bsi.ac.id ${ }^{[1]}$, hekhmatyar@gmail.com ${ }^{[2]}$, feri.fpo@bsi.ac.id ${ }^{[3]}$
}

\begin{abstract}
Abstrak- In this era of globalization along with the development and progression of increasingly sophisticated technology, the flow of information must be delivered quickly and accurately. Widespread activity and human need for information makes it requires a computer with Internet access to be able to resolve the issues and activities quickly and accurately.Technological developments in the field of communication today helped humans in various areas of life, including in the world of tourism. One of the technological advances in the field of communication that can be utilized for the provision of information and promotion of tourism is the internet. Indonesia has pontesi state of tourism in different regions of one of them in the area of western Java brass. Based on the above understanding, the tourism point of view as an alternative to increase local revenue. In order to promote tourism in the region of western Java brass we made a tourism website in order to facilitate the community in accessing any information relating to tourism in the region of western Java brass.Muaragembong Regency is one of the tourist centers potensional in West Java province, where a great variety of cultural and interesting attractions as well as typical food full of flavor.Come and enjoy the beauty and the natural beauty of the exotic nature, rich culture and diverse challenges. IntisariPerkembangan teknologi di bidang komunikasi saat ini banyak membantu manusia di berbagai bidang kehidupan,termasuk didalam dunia pariwisata. Salah satu kemajuan teknologi di bidang komunikasi yang dapat di manfaatkan untuk penyediaan informasi dan promosi kepariwisataan adalah internet. Negara indonesia memiliki pontesi kepariwisataan di berbagai daerah salah satunya di daerah Muaragembong jawa barat. Berdasarkan pemahaman di atas maka pariwisata di pandang sebagai salah satu alternatif untuk meningkatkan pendapatan daerah. Demi mempromosikan pariwisata di daerah Muaragembong jawa barat kami membuat sebuah website kepariwisataan agar mempermudah masyarakat dalam mengakes segala informasi yang berkaitan dengan pariwisata di daerah Muaragembong jawa barat.Kecamatan Muaragembong merupakan salah satu sentra wisata potensional di Provinsi Jawa Barat, dimana banyak ragam budaya dan obyek wisata yang menarik serta makanan khas yang penuh akan cita rasa. Datang dan nikmatilah keindahan serta keasrian alam yang alami nan eksotis, kaya akan tantangan dan culture yang beragam.
\end{abstract}

Kata Kunci- Sistem Informasi, E-Pariwisata, Teknologi Informasi.

\section{Pendahuluan}

Dalam era globalisasi ini seiring dengan perkembangan dan kemajuan teknologi yang semakin canggih,maka arus informasi harus disampaikan secara cepat dan akurat.
Meluasnya kegiatan dan kebutuhan manusia akan informasi membuatnya membutuhkan komputer yang memiliki akses internet untuk dapat menyelesaikan masalah dan kegiatan dengan cepat dan akurat.

Perkembangan teknologi di bidang komunikasi saat ini banyak membantu manusia di berbagai bidang kehidupan,termasuk didalam dunia pariwisata. Salah satu kemajuan teknologi di bidang komunikasi yang dapat di manfaatkan untuk penyediaan informasi dan promosi kepariwisataan adalah internet. Negara indonesia memiliki pontesi kepariwisataan di berbagai daerah salah satunya di daerah Muaragembong jawa barat. Berdasarkan pemahaman di atas maka pariwisata di pandang sebagai salah satu alternatif untuk meningkatkan pendapatan daerah. Demi mempromosikan pariwisata di daerah Muaragembong jawa barat kami membuat sebuah website kepariwisataan agar mempermudah masyarakat dalam mengakes segala informasi yang berkaitan dengan pariwisata di daerah Muaragembong jawa barat.

Kecamatan Muaragembong merupakan salah satu sentra wisata potensional di Provinsi Jawa Barat, dimana banyak ragam budaya dan obyek wisata yang menarik serta makanan khas yang penuh akan cita rasa.

Datang dan nikmatilah keindahan serta keasrian alam yang alami nan eksotis, kaya akan tantangan dan culture yang beragam.

\section{TINJAUAN PUSTAKA}

TABEL 1. PENELITIAN TERKAIT

\begin{tabular}{|c|c|c|c|c|}
\hline No & $\begin{array}{c}\text { Nama } \\
\text { Peneliti } \\
\text { dan } \\
\text { Tahun }\end{array}$ & Masalah & Metode & Hasil \\
\hline 1 & $\begin{array}{l}\text { Ronnie } \\
\text { Cheung, } \\
\text { Pamela } \\
\text { Lam, } \\
2009\end{array}$ & $\begin{array}{l}\text { How } \\
\text { Travel } \\
\text { Agency } \\
\text { Survive } \\
\text { in e- } \\
\text { Business } \\
\text { World? }\end{array}$ & $\begin{array}{l}\text { Changing } \\
\text { Role of } \\
\text { Travel } \\
\text { Agency: } \\
\text { 1. Commi- } \\
\quad \text { sion Caps } \\
\quad \text { and Cuts; } \\
\text { 2. The } \\
\quad \text { Internet }\end{array}$ & $\begin{array}{l}\text { 1. Informati } \\
\text { on } \\
\text { brokers to } \\
\text { pass } \\
\text { informa- } \\
\text { tion from } \\
\text { product } \\
\text { suppliers } \\
\text { to }\end{array}$ \\
\hline
\end{tabular}




\begin{tabular}{|c|c|c|c|c|}
\hline No & $\begin{array}{c}\text { Nama } \\
\text { Peneliti } \\
\text { dan } \\
\text { Tahun }\end{array}$ & Masalah & Metode & Hasil \\
\hline & & & $\begin{array}{l}\text { and the } \\
\text { Travel } \\
\text { Industry. }\end{array}$ & $\begin{array}{l}\text { customers } \\
\text { 2. Transac- } \\
\text { tions } \\
\text { processor } \\
\text { s to print } \\
\text { ticket or } \\
\text { forward } \\
\text { money; } \\
\text { 3. Advisors } \\
\text { to provide } \\
\text { value } \\
\text { added } \\
\text { informati } \\
\text { on to their } \\
\text { customers } \\
\text {, assisting } \\
\text { them in } \\
\text { their } \\
\text { choices of } \\
\text { specific } \\
\text { products } \\
\text { and desti- } \\
\text { nations. }\end{array}$ \\
\hline
\end{tabular}

E-pariwisata merupakan sebuah Website atau aplikasi yang mendukung Kegiatan perjalanan untuk memenuhi rasa ingin tahu, untuk keperluan yang bersifat rekreatif dan edukatif, dikategorikan sebagai kegiatan wisata. Kegiatan wisata kiranya dapat dirumuskan sebagai suatu perjalanan dan persinggahan yang dilakukan untuk berbagai maksud dan tujuan, tetapi tidak untuk tinggal menetap ditempat yang dikunjungi atau disinggahi, atau untuk melakukan pekerjaan-pekerjaan yang mendapatkan upah.

Website adalah suatu halaman web yang saling berhubungan yang umumnya berada pada peladen yang sama berisikan kumpulan informasi yang disediakan secara perorangan, kelompok, atau organisasi.

Sebuah situs web biasanya ditempatkan setidaknya pada sebuah server web yang dapat diakses melalui jaringan seperti Internet, ataupun jaringan wilayah lokal (LAN) melalui alamat Internet yang dikenali sebagai URL. Gabungan atas semua situs yang dapat diakses publik di Internet disebut pula sebagai World Wide Web atau lebih dikenal dengan singkatan WWW. Meskipun setidaknya halaman beranda situs Internet umumnya dapat diakses publik secara bebas, pada praktiknya tidak semua situs memberikan kebebasan bagi publik untuk mengaksesnya, beberapa situs web mewajibkan pengunjung untuk melakukan pendaftaran sebagai anggota, atau bahkan meminta pembayaran untuk dapat menjadi aggota untuk dapat mengakses isi yang terdapat dalam situs web tersebut, misalnya situs-situs yang menampilkan pornografi, situs-situs berita, layanan surel (e-mail), dan lain-lain. Pembatasan-pembatasan ini umumnya dilakukan karena alasan keamanan, menghormati privasi, atau karena tujuan komersial tertentu.

Metode SDLC Waterfall merupakan metode dalam mengerjakan pengembangan software dimana setiap fase harus dikerjakan dulu sebelum fase berikutnya dijalankan.

Sistem informasi merupakan kombinasi dari manusia, fasilitas atau alat teknologi, media, prosedur dan pengendalian yang bermaksud menata jaringan komunikasi yang penting, proses atas transaksi-transaksi tertentu dan rutin, membantu manajemen dan pemakai intern dan ekstern dan menyediakan dasar pengambilan keputusan yang tepat.

\section{Metodologi Penelitian}

Dalam penelitian ini metodologi yang digunakan adalah dengan melakukan deskriptif kualitatif yaitu penelitian yang disampaikan dalam bentuk deskripsi.

\section{A. Teknik Pengumpulan Data}

Teknik pengumpulan data yang kami gunakan dalam racang bangun aplikasi e-pariwisata adalah:

\section{1) Metode Pengumpulan Data}

Metode pengumpulan data dengan cara mencari informasi melalui internet khususnya observasi melalui website www.keckotabaru.jambikota.go.id

\section{2) Studi Pustaka}

Metode pengumpulan data dari perpustakaan dengan cara menggunakan buku-buku yang berhubungan dengan sistem informasi, pemrograman web, mencari data melalui website serta sumber lain yang bisa dijadikan referensi.

\section{B. Kerangka Penelitian}

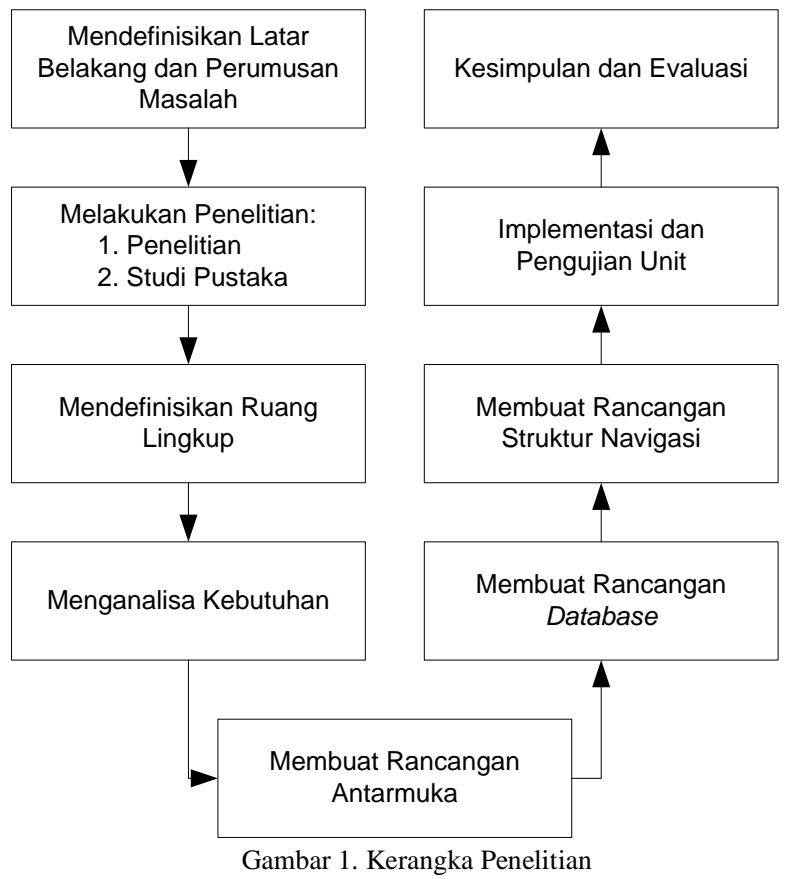




\section{PEMBAhasAn}

A. Analisa Kebutuhan

Berikut Analisa Kebutuhan system E-Pariwisata

TABEL 2. ANALISA KeBUTUHAN SISTEM

\begin{tabular}{|l|l|l|}
\hline No & Level & Analisa Kebutuhan \\
\hline 1. & Admin & $\begin{array}{l}\text { Melihat,Tambah,Edit,Hapus : Data } \\
\text { Objek wisata wisata dan data hotel dan } \\
\text { penginapan ,Data pesan Pengunjung dan } \\
\text { Logout }\end{array}$ \\
\hline 2 & Pengunjung & $\begin{array}{l}\text { Dapat melihat : Data Lembaga yang } \\
\text { isinya Visi Misi,tugas fungsi, program } \\
\text { kerja,pelayanan dan Data Objek } \\
\text { wisata,hotel dan penginapan, dan Data } \\
\text { Kepegawaian yg isinya Struktur } \\
\text { organisasi Disparbud Muaragembong } \\
\text { dan Data Pegawai . katar mengisi komentar dengan } \\
\text { Dapat mentar. } \\
\text { mengisi form komentar. }\end{array}$ \\
\hline
\end{tabular}

\section{B. Perancangan Database}

\section{1) Entity Relationship Diagram (ERD)}

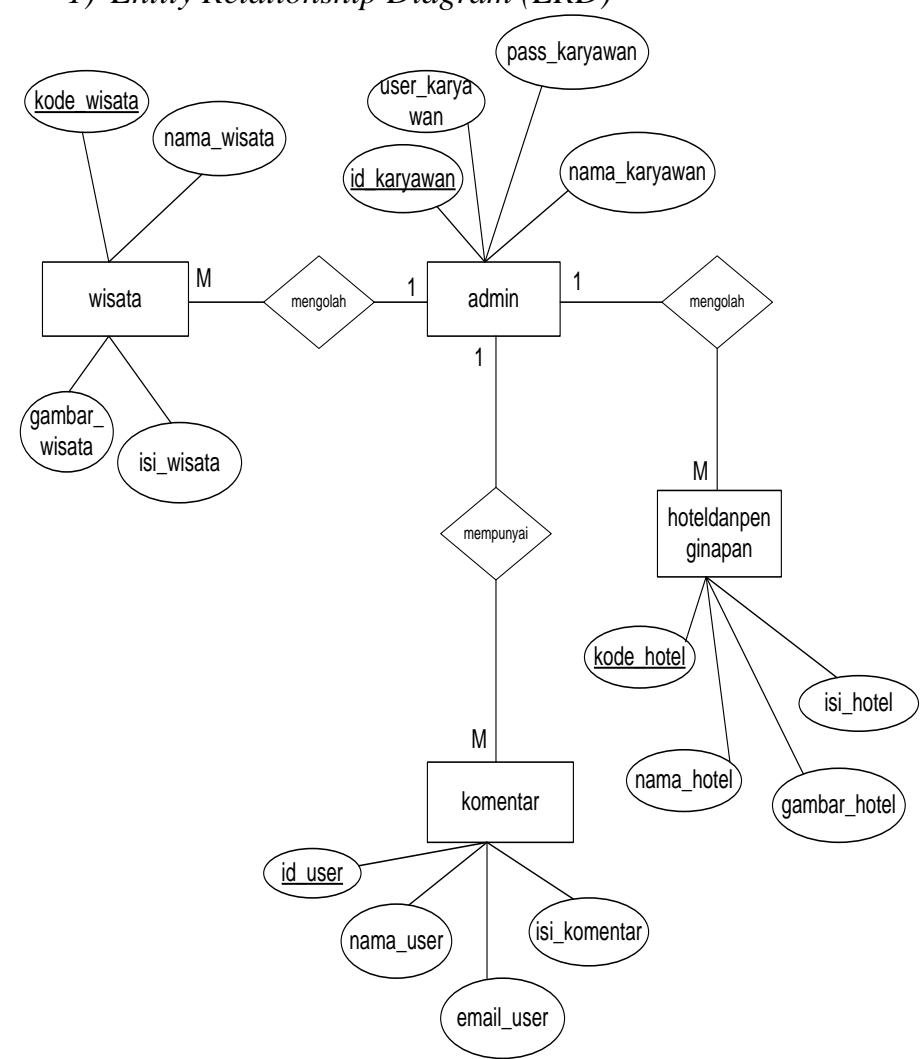

Gambar 2. Entity Relationship Diagram

\section{2) Logical Record Structure}

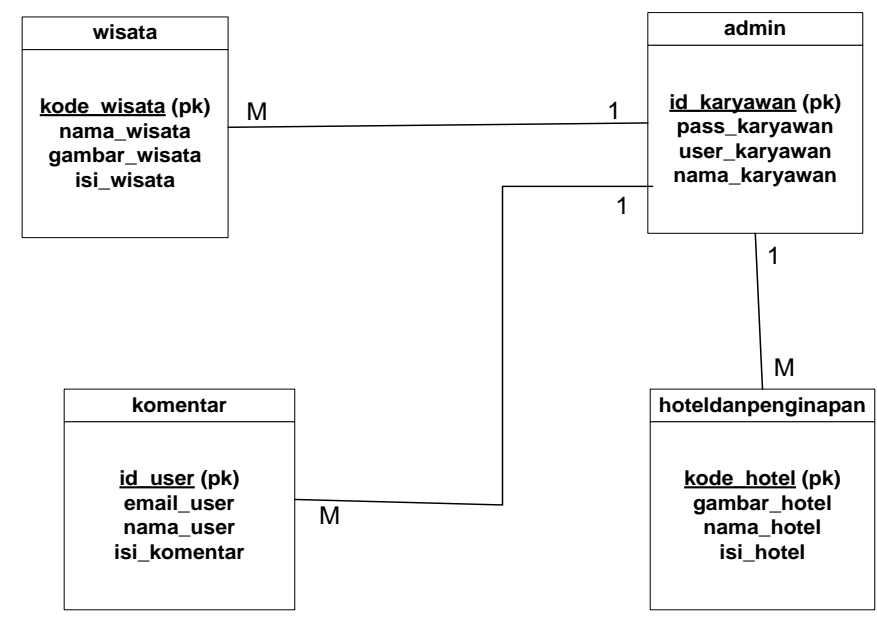

Gambar 3. Logical Record Stucture (LRS)

3) Spesifikasi File

a) Spesifikasi File Tabel Admin

$\begin{array}{ll}\text { Nama File } & : \text { Admin } \\ \text { Akronim } & \text { : admin } \\ \text { Fungsi } & \text { : Untuk Login } \\ \text { Tipe File } & \text { : File Master } \\ \text { Organisasi File } & \text { : Indexed Sequ } \\ \text { Akses File } & \text { : Random } \\ \text { Media } & \text { : Hardisk } \\ \text { Panjang Record } & : \text { 121 record } \\ \text { Kunci Filed } & : \text { id_karyawan } \\ \text { Software } & : \text { Mysql }\end{array}$

b) Spesifikasi File Tabel Hotel dan Penginapan

Nama File : Hotel dan Penginapan

Akronim : hoteldanpenginapan

Fungsi : Untuk mengisi data hotel

Tipe File : File Master

Organisasi File : Indexed Sequential

Akses File : Random

Media : Hardisk

Panjang Record : 131 record

Kunci Filed : kode_hotel

Software : Mysql

c) Spesifikasi File Tabel Komentar

Nama File : Komentar

Akronim : komentar

Fungsi : Untuk meninggalkan pesan atau

komentar dari user

Tipe File : File Master

Organisasi File : Indexed Sequential

Akses File : Random

Media : Hardisk

Panjang Record : 61 record

Kunci Filed : id_user

Software : Mysql 
d) Spesifikasi File Tabel Wisata

$\begin{array}{ll}\text { Nama File } & \text { : Wisata } \\ \text { Akronim } & \text { : wisata } \\ \text { Fungsi } & \text { : Untuk mengisi data wisata } \\ \text { Tipe File } & \text { : File Master } \\ \text { Organisasi File } & \text { : Indexed Sequential } \\ \text { Akses File } & \text { : Random } \\ \text { Media } & \text { : Hardisk } \\ \text { Panjang Record } & : \text { 136 record } \\ \text { Kunci Field } & : \text { kode } \\ \text { Software } & : \text { Mysql }\end{array}$

C. Perancangan Antar Muka

1) Admin

a) Halaman Antar Muka Admin Login

\begin{tabular}{|l|l|l|l|}
\hline \multicolumn{3}{|l|}{} \\
\hline Username : & \multicolumn{3}{|l|}{ xxxxxxxxxxx } \\
\hline Password : & Xxxxxxxxxx & \\
\hline & Login & \\
\hline
\end{tabular}

Gambar 4. Rancangan Antarmuka Halaman Login Admin

2) User

a) Rancangan Antar Muka Halaman Home

\begin{tabular}{|c|c|c|c|c|c|c|}
\hline \multicolumn{7}{|c|}{ Header } \\
\hline Home & Lembaga & & \&Budaya & Kepegawaian & Hubungi Kami & Login Admin \\
\hline \multicolumn{7}{|c|}{ Slide Banner } \\
\hline \multicolumn{3}{|c|}{$\begin{array}{l}\text { Tumbnail } \\
\text { Wisata }\end{array}$} & $\begin{array}{l}\text { Tumbnail } \\
\text { Wisata }\end{array}$ & $\begin{array}{l}\text { Tumbnail } \\
\text { Hotel }\end{array}$ & $\begin{array}{l}\text { Tumbnail } \\
\text { Hotel }\end{array}$ & \\
\hline \multicolumn{7}{|c|}{ Footer } \\
\hline
\end{tabular}

Gambar 5. Rancangan Halaman Home

\section{Budaya}

b) Rancangan Antar Muka Halaman Wisata dan

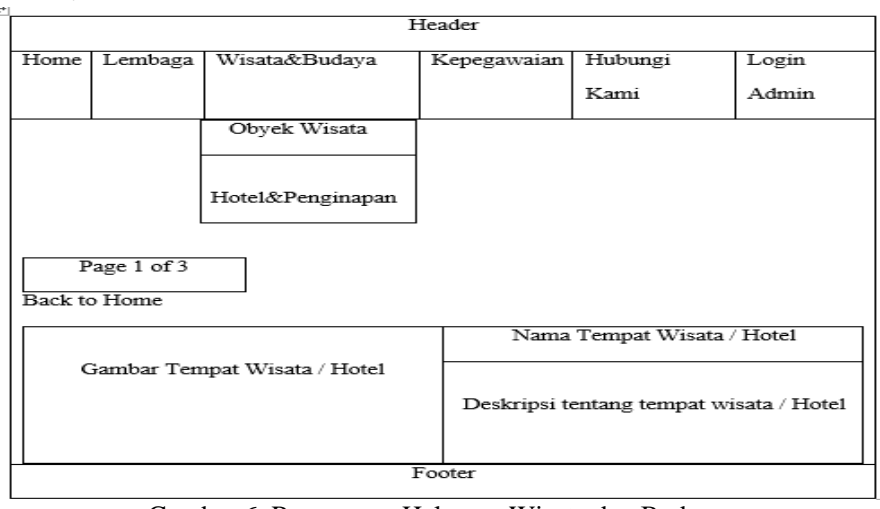

Gambar 6. Rancangan Halaman Wisata dan Budaya

\section{Perancangan Struktur Navigasi}

1) Struktur Navigasi Halaman Administrator

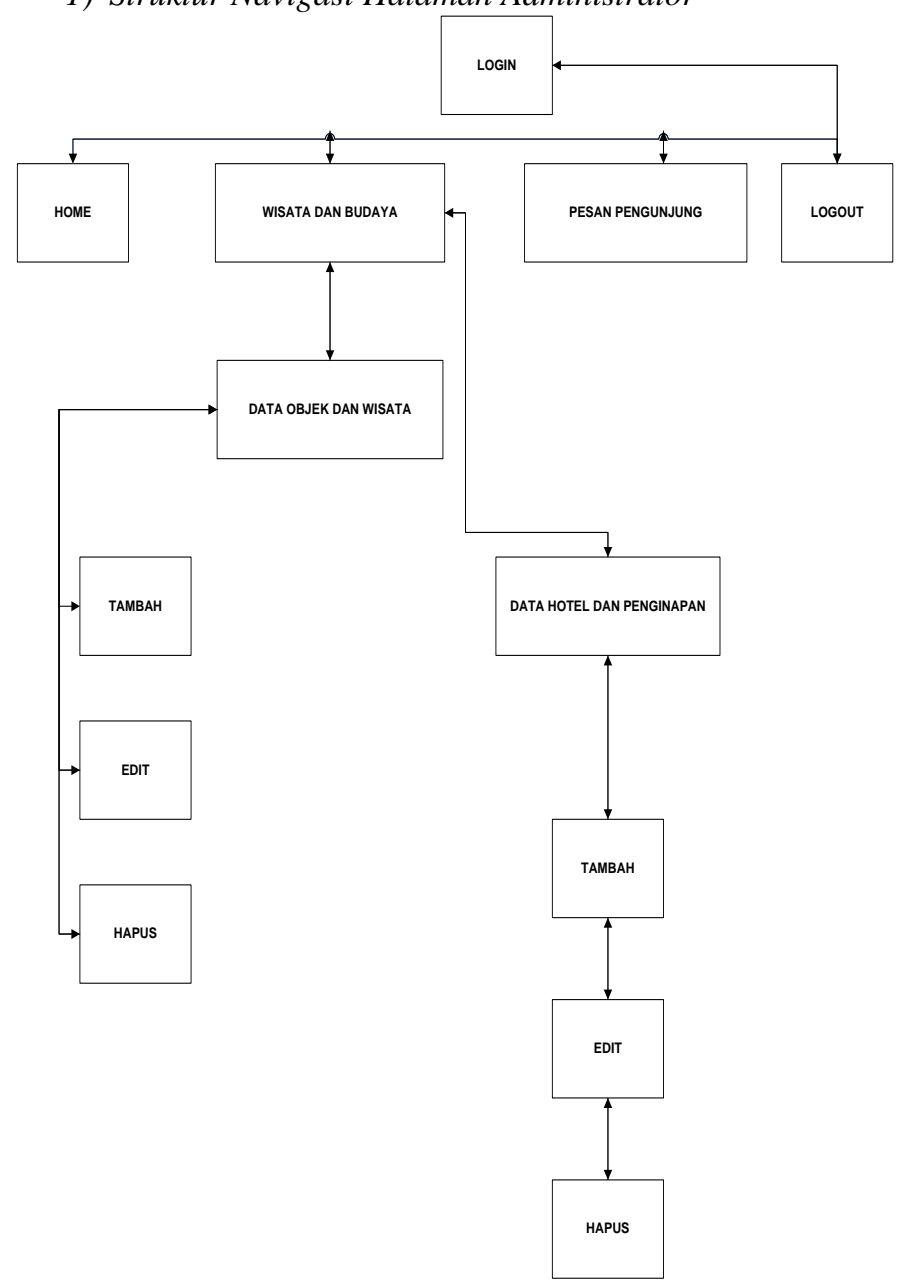

Gambar 7. Struktur navigasi halaman admin

Penjelasan untuk masing-masing halaman admin adalah sebagai berikut:

a) Home

Pada menu ini berisikan ucapan Selamat Datang kepada admin yang berhasil mengakses halaman admin.

b) Wisata dan Budaya

Menu ini berisikan 2 sub menu yaitu data objek dan wisata, pada sub menu ini admin dapat menambah, mengubah dan menghapus data wisata. Sedangkan sub menu hotel dan penginapan addmin dapat menambah, mengubah dan menghapus data hotel dan penginapan.

c) Pesan Pengunjung

Pada menu ini admin dapat melihat data komentar atau pesan pengunjung.

d) Log Out

Pada menu ini admin dapat keluar dari halaman admin. 
2) Struktur Navigasi Halaman Pengunjung

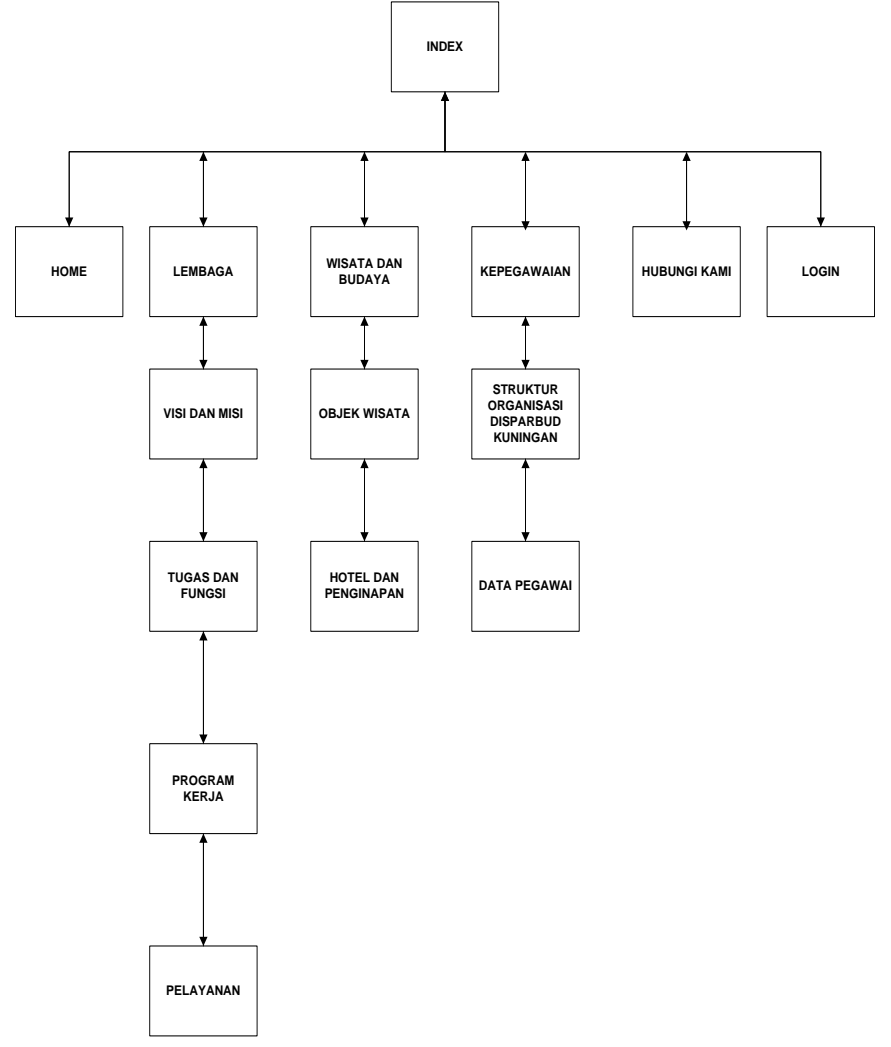

Gambar 8. Rancangan Struktur Navigasi

Penjelasan untuk masing-masing halaman pengunjung adalah sebagai berikut:

a) Index atau Home

Pada menu ini menampilkan sebagian gambaran dan informasi tentang wisata yang ada di Muaragembong.

b) Lembaga

Menu ini menampilkan informasi tentang visi dan misi, tugas dan fungsi, program kerja dan pelayanan pada dinas pariwisata dan kebudayaan.

c) Wisata dan Budaya

Menu ini berisikan tentang beberapa informasi obyek wisata dan hotel.

d) Kepegawaian

Menu ini menampilkan informasi struktur organisasi dinas pariwisata dan kebudayaan Muaragembong dan data pegawai.

e) Hubungi Kami

Menu ini berisikan informasi kontak dan form pengisian komentar pengunjung.

f) Login Admin.

Pada menu ini hanya bisa diakses oleh admin, berisikan form untuk masuk ke halaman admin.

\section{E. Pengujian Website}

\section{1) Pengujian Halaman Login Admin}

TABel 2. Blackbox Testing HaLaman Login ADMIN

\begin{tabular}{|c|c|c|c|c|c|}
\hline No. & $\begin{array}{l}\text { Skenario } \\
\text { Pengujian }\end{array}$ & $\begin{array}{l}\text { Test } \\
\text { Case }\end{array}$ & $\begin{array}{l}\text { Hasil } \\
\text { yang } \\
\text { Dihara } \\
\text { pkan }\end{array}$ & $\begin{array}{l}\text { Hasil } \\
\text { Uji }\end{array}$ & $\begin{array}{l}\text { Kesi } \\
\text { mpul } \\
\text { an }\end{array}$ \\
\hline 1 & $\begin{array}{l}\text { Mengosong } \\
\text { kan semua } \\
\text { input /salah } \\
\text { satu data } \\
\text { login } \\
\text { kemudian } \\
\text { langsung } \\
\text { klik tombol } \\
\text { login }\end{array}$ & $\begin{array}{l}\text { Userna } \\
\text { me : } \\
\text { (kosong) } \\
\text { Passwor } \\
\text { d : } \\
\text { (kosong) }\end{array}$ & $\begin{array}{l}\text { Sistem } \\
\text { tidak } \\
\text { masuk } \\
\text { ke } \\
\text { akses } \\
\text { login }\end{array}$ & $\begin{array}{l}\text { Sesuai } \\
\text { harapan }\end{array}$ & valid \\
\hline 2 & $\begin{array}{l}\text { Menginput } \\
\text { data dengan } \\
\text { isian yang } \\
\text { salah }\end{array}$ & $\begin{array}{l}\text { Userna } \\
\text { me : } \\
\text { (Benar) } \\
\text { Passwor } \\
\text { d : } \\
\text { (salah) } \\
\text { Atau } \\
\text { Userna } \\
\text { me : } \\
\text { (Salah) } \\
\text { Passwor } \\
\text { d : } \\
\text { (Benar) }\end{array}$ & $\begin{array}{l}\text { Sistem } \\
\text { tidak } \\
\text { masuk } \\
\text { ke } \\
\text { akses } \\
\text { login }\end{array}$ & $\begin{array}{l}\text { Sesuai } \\
\text { harapan }\end{array}$ & valid \\
\hline 3 & $\begin{array}{l}\text { Menginput } \\
\text { data dengan } \\
\text { isian yang } \\
\text { benar }\end{array}$ & $\begin{array}{l}\text { Userna } \\
\text { me : } \\
\text { (Benar) } \\
\text { Passwor } \\
\text { d : } \\
\text { (Benar) }\end{array}$ & $\begin{array}{l}\text { Sistem } \\
\text { masuk } \\
\text { ke } \\
\text { akses } \\
\text { login } \\
\text { dan } \\
\text { menuju } \\
\text { ke } \\
\text { Halama } \\
\text { n } \\
\text { Home } \\
\text { Admin }\end{array}$ & $\begin{array}{l}\text { Sesuai } \\
\text { harapan }\end{array}$ & valid \\
\hline 4. & $\begin{array}{l}\text { Mengetikka } \\
\mathrm{n} \text { username } \\
\text { dan } \\
\text { password } \\
\text { tapi tidak } \\
\text { diisi } \\
\text { kemudian } \\
\text { klik login }\end{array}$ & $\begin{array}{l}\text { Userna } \\
\text { me : } \\
\text { (kosong) } \\
\text { Passwor } \\
\text { d : } \\
\text { (kosong) }\end{array}$ & $\begin{array}{l}\text { Sistem } \\
\text { tidak } \\
\text { masuk } \\
\text { ke } \\
\text { akses } \\
\text { login }\end{array}$ & $\begin{array}{l}\text { Sesuai } \\
\text { harapan }\end{array}$ & valid \\
\hline
\end{tabular}


2) Pengujian Halaman Data Master

TABEl 3. TESTing Halaman Data Master

\begin{tabular}{|c|c|c|c|c|c|c|c|c|c|c|c|}
\hline \multirow{2}{*}{ No. } & \multirow{2}{*}{$\begin{array}{l}\text { Skenario } \\
\text { Pengujian }\end{array}$} & \multirow{2}{*}{$\begin{array}{l}\text { Test } \\
\text { Case }\end{array}$} & \multirow[b]{2}{*}{$\begin{array}{l}\text { Hasil } \\
\text { yang } \\
\text { Diharap } \\
\text { kan }\end{array}$} & \multirow{2}{*}{$\begin{array}{l}\text { Hasil } \\
\text { Uji }\end{array}$} & \multirow{2}{*}{$\begin{array}{l}\text { Kesi } \\
\text { mpul } \\
\text { an }\end{array}$} & & & & & & \\
\hline & & & & & & & & $\begin{array}{l}\text { an } \\
\text { kemudia } \\
\mathrm{n} \quad \text { klik }\end{array}$ & & & \\
\hline \multirow[t]{4}{*}{1} & \multirow{4}{*}{$\begin{array}{l}\text { Penambahan } \\
\text { Data Baru } \\
\text { Data Hotel } \\
\text { Dan } \\
\text { Penginapan }\end{array}$} & \multirow{4}{*}{$\begin{array}{l}\text { Klik } \\
\text { tambah } \\
\text { data } \\
\text { Hotel } \\
\text { Dan } \\
\text { Penginap } \\
\text { an } \\
\text { kemudia } \\
\text { n } \\
\text { mengisi } \\
\text { isian } \\
\text { nama } \\
\text { Hotel } \\
\text { Dan } \\
\text { Penginap } \\
\text { an, } \\
\text { mengupl } \\
\text { oad } \\
\text { gambar, } \\
\text { mengisi } \\
\text { isi Hotel } \\
\text { Dan } \\
\text { Penginap } \\
\text { an } \\
\text { kemudia } \\
\text { n klik } \\
\text { submit }\end{array}$} & \multirow{4}{*}{$\begin{array}{l}\text { Muncul } \\
\text { alert data } \\
\text { dan } \\
\text { gambar } \\
\text { berhasil } \\
\text { di upload } \\
\text { dan data } \\
\text { berhasil } \\
\text { tersimpa } \\
\text { n }\end{array}$} & \multirow{4}{*}{$\begin{array}{l}\text { Sesuai } \\
\text { harapa } \\
n\end{array}$} & \multirow[t]{4}{*}{ Valid } & & & & & & \\
\hline & & & & & & 3 & $\begin{array}{l}\text { Mengedit } \\
\text { Data Hotel } \\
\text { Dan } \\
\text { Penginapan }\end{array}$ & $\begin{array}{l}\text { Klik edit } \\
\text { kemudia } \\
\mathrm{n} \text { ubah } \\
\text { salah } \\
\text { satu isian } \\
\text { dan klik } \\
\text { update }\end{array}$ & $\begin{array}{l}\text { Muncul } \\
\text { alert data } \\
\text { terupdate }\end{array}$ & $\begin{array}{l}\text { Sesuai } \\
\text { harapa } \\
\mathrm{n}\end{array}$ & valid \\
\hline & & & & & & 4 & $\begin{array}{l}\text { Menhapus } \\
\text { Data Hotel } \\
\text { Dan } \\
\text { Penginapan }\end{array}$ & $\begin{array}{l}\text { Klik } \\
\text { hapus } \\
\text { kemudia } \\
\text { n muncul } \\
\text { alert “" } \\
\text { Yakin } \\
\text { Mau } \\
\text { diHapus } \\
\text { “ lalu } \\
\text { klik OK }\end{array}$ & $\begin{array}{l}\text { Muncul } \\
\text { alert } \\
\text { "data } \\
\text { telah } \\
\text { terhapus } \\
\text { " }\end{array}$ & $\begin{array}{l}\text { Sesuai } \\
\text { harapa } \\
\mathrm{n}\end{array}$ & valid \\
\hline & & & & & & 5 & $\begin{array}{l}\text { Pencarian } \\
\text { Data }\end{array}$ & $\begin{array}{l}\text { Input di } \\
\text { kolom } \\
\text { pencaria } \\
\mathrm{n} \\
\text { berdasar } \\
\text { kan kode } \\
\text { Hotel } \\
\text { Dan }\end{array}$ & $\begin{array}{l}\text { Muncul } \\
\text { data } \\
\text { berdasar } \\
\text { kan } \\
\text { pencaria } \\
\text { n yang } \\
\text { sudah } \\
\text { kita }\end{array}$ & $\begin{array}{l}\text { Sesuai } \\
\text { harapa } \\
\mathrm{n}\end{array}$ & valid \\
\hline \multirow[t]{3}{*}{2} & \multirow{3}{*}{$\begin{array}{l}\text { Mengupdate } \\
\text { Data Hotel } \\
\text { Dan } \\
\text { Penginapan }\end{array}$} & \multirow{3}{*}{$\begin{array}{l}\text { Klik } \\
\text { tambah } \\
\text { data } \\
\text { Hotel } \\
\text { Dan } \\
\text { Penginap } \\
\text { an } \\
\text { kemudia } \\
\text { n } \\
\text { mengisi } \\
\text { isian } \\
\text { nama } \\
\text { Hotel } \\
\text { Dan } \\
\text { Penginap } \\
\text { an, } \\
\text { mengupl } \\
\text { oad } \\
\text { gambar, } \\
\text { mengisi } \\
\text { isi Hotel } \\
\text { Dan } \\
\text { Penginap }\end{array}$} & \multirow{3}{*}{$\begin{array}{l}\text { Semua } \\
\text { isian } \\
\text { yang } \\
\text { sudah } \\
\text { kita isi } \\
\text { hilang } \\
\text { dan } \\
\text { semua } \\
\text { kolom } \\
\text { kosong }\end{array}$} & \multirow{3}{*}{$\begin{array}{l}\text { Sesuai } \\
\text { harapa } \\
n\end{array}$} & \multirow[t]{3}{*}{ Valid } & & & $\begin{array}{l}\text { Penginap } \\
\text { an }\end{array}$ & input & & \\
\hline & & & & & & 6 & $\begin{array}{l}\text { Pencarian } \\
\text { Data }\end{array}$ & $\begin{array}{l}\text { Input di } \\
\text { kolom } \\
\text { pencaria } \\
\text { n } \\
\text { berdasar } \\
\text { kan } \\
\text { Nama } \\
\text { Hotel } \\
\text { Dan } \\
\text { Penginap } \\
\text { an }\end{array}$ & $\begin{array}{l}\text { Muncul } \\
\text { data } \\
\text { berdasar } \\
\text { kan } \\
\text { pencaria } \\
\text { n yang } \\
\text { sudah } \\
\text { kita } \\
\text { input }\end{array}$ & $\begin{array}{l}\text { Sesuai } \\
\text { harapa } \\
n\end{array}$ & valid \\
\hline & & & & & & 7 & $\begin{array}{l}\text { Pencarian } \\
\text { Data }\end{array}$ & $\begin{array}{l}\text { Input di } \\
\text { kolom } \\
\text { pencaria } \\
\mathrm{n} \\
\text { berdasar } \\
\text { kan Isi } \\
\text { Hotel } \\
\text { Dan } \\
\text { Penginap } \\
\text { an }\end{array}$ & $\begin{array}{l}\text { Muncul } \\
\text { data } \\
\text { berdasar } \\
\text { kan } \\
\text { pencaria } \\
\text { n yang } \\
\text { sudah } \\
\text { kita } \\
\text { input }\end{array}$ & $\begin{array}{l}\text { Sesuai } \\
\text { harapa } \\
\mathrm{n}\end{array}$ & valid \\
\hline
\end{tabular}




\section{EVALUASI DAN KESIMPULAN}

\section{A. Evaluasi}

Pada pengujian ini penulis melakukan penyebaran kuesioner kepada pengguna akhir system yaitu traveler dan masyarakat sekitar sebanyak 20 Orang.

TABEL 4. HASIL KUISIONER

\begin{tabular}{|c|c|c|c|c|c|c|}
\hline No & Kode & Pertayaan & STS & TS & $\mathbf{S}$ & SS \\
\hline 1 & $\mathrm{C} 1$ & $\begin{array}{l}\text { Aplikasi sistem } \\
\text { memberikan } \\
\text { informasi yang } \\
\text { tepat sesuai } \\
\text { dengan yang } \\
\text { anda butuhkan? }\end{array}$ & 0 & 0 & 10 & 10 \\
\hline 2 & $\mathrm{C} 2$ & $\begin{array}{c}\text { Apakah isi } \\
\text { informasi yang } \\
\text { dihasilkan } \\
\text { sistem } \\
\text { memenuhi } \\
\text { kebutuhan } \\
\text { anda? }\end{array}$ & 0 & 1 & 16 & 3 \\
\hline 3 & $\mathrm{C} 3$ & $\begin{array}{l}\text { Apakah sistem } \\
\text { memberikan } \\
\text { laporan sesuai } \\
\text { dengan yang } \\
\text { anda butuhkan? }\end{array}$ & 0 & 2 & 16 & 2 \\
\hline 4 & $\mathrm{C} 4$ & $\begin{array}{l}\text { Apakah sistem } \\
\text { memberikan } \\
\text { informasi yang } \\
\text { cukup sesuai } \\
\text { dengan yang } \\
\text { anda butuhkan? }\end{array}$ & 0 & 1 & 16 & 3 \\
\hline 5 & A1 & $\begin{array}{l}\text { Apakah sistem } \\
\text { ini akurat? }\end{array}$ & 0 & 2 & 16 & 2 \\
\hline 6 & $\mathrm{~A} 2$ & $\begin{array}{c}\text { Apakah anda } \\
\text { puas dengan } \\
\text { akurasi sistem? }\end{array}$ & 0 & 4 & 14 & 2 \\
\hline 7 & F1 & $\begin{array}{c}\text { Apakah } \\
\text { menurut anda } \\
\text { hasil disajikan } \\
\text { dalam format } \\
\text { yang berguna? }\end{array}$ & 0 & 3 & 11 & 6 \\
\hline 8 & $\mathrm{~F} 2$ & $\begin{array}{c}\text { Apakah } \\
\text { informasi yang } \\
\text { dihasilkan } \\
\text { sistem jelas? }\end{array}$ & 0 & 0 & 16 & 4 \\
\hline 9 & E1 & $\begin{array}{l}\text { Apakah sistem } \\
\text { ini ramah } \\
\text { pengguna? }\end{array}$ & 0 & 1 & 15 & 4 \\
\hline 10 & E2 & $\begin{array}{c}\text { Apakah sistem } \\
\text { mudah } \\
\text { digunakan? }\end{array}$ & 1 & 2 & 13 & 4 \\
\hline
\end{tabular}

\begin{tabular}{|c|c|c|c|c|c|c|} 
& T1 & $\begin{array}{c}\text { Apakah anda } \\
\text { menerima } \\
\text { informasi yang } \\
\text { anda butuhkan } \\
\text { tepat waktu? }\end{array}$ & 0 & 0 & 17 & 3 \\
\hline 12 & $\mathrm{~T} 2$ & $\begin{array}{c}\text { Apakah sistem } \\
\text { menyediakan } \\
\text { informasi } \\
\text { terbaru? }\end{array}$ & 0 & 4 & 15 & 1 \\
\hline
\end{tabular}

Dari tabel diatas nomor 1-12 merupakan pertanyan yang diajukan kepada responden. Sedangkan 1-4 adalah pilihan nilai program tersebut, keterangannya ialah sebagai berikut:

1 = Sangat Tidak Setuju

$2=$ Tidak Setuju

$3=$ Setuju

4 = Sangat Setuju

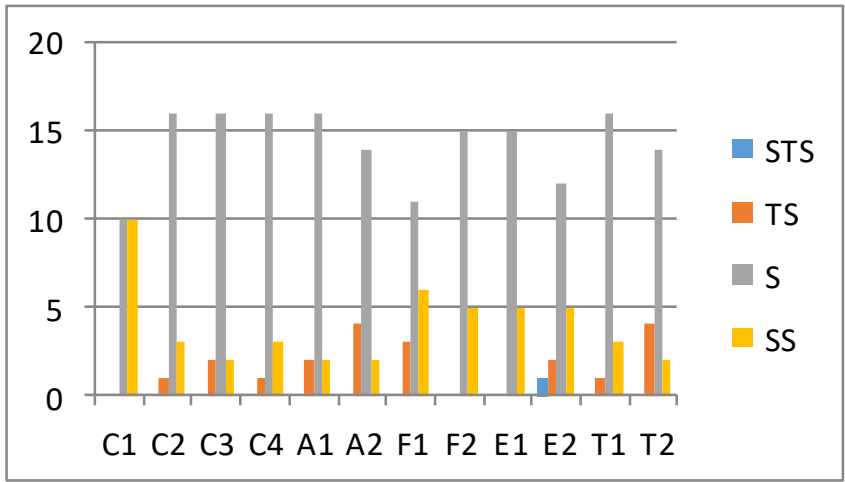

Gambar 9. Grafik Penilaian Kuestioner

Dari grafik di atas, maka dapat dilihat:

- Tingkat aplikasi sistem memberikan informasi yang tepat sesuai dengan kebutuhan, 10 pengguna menjawab "Setuju" dan 10 pengguna menjawab "Sangat Setuju".

- Tingkat isi informasi yang dihasilkan sistem memenuhi kebutuhan, 1 pengguna menjawab "Tidak Setuju", 16 pengguna menjawab "Setuju" dan 3 pengguna menjawab "Sangat Setuju".

- Tingkat sistem memberikan laporan sesuai dengan yang dibutuhkan, 2 pengguna menjawab "Tidak Setuju", 16 pengguna menjawab "Setuju" dan 2 pengguna menjawab "Sangat Setuju".

- Tingkat sistem memberikan informasi yang cukup sesuai dengan yang dibutuhkan, 1 pengguna menjawab "Tidak Setuju", 16 pengguna menjawab "Setuju" dan 3 pengguna menjawab "Sangat Setuju".

- Tingkat sistem ini akurat, 2 pengguna menjawab "Tidak Setuju", 16 pengguna menjawab "Setuju" dan 2 pengguna menjawab "Sangat Setuju”.

- Tingkat kepuasan dengan akurasi sistem, 4 pengguna menjawab "Tidak Setuju", 14 pengguna menjawab "Setuju" dan 2 pengguna menjawab "Sangat Setuju".

- Tingkat hasil yang disajikan dalam format yang berguna, 3 pengguna menjawab "Tidak Setuju", 11 
pengguna menjawab "Setuju" dan 6 pengguna menjawab "Sangat Setuju".

- Tingkat informasi yang dihasilkan sistem jelas, 15pengguna menjawab "Setuju" dan 5 pengguna menjawab "Sangat Setuju".

- Tingkat sistem ini ramah pengguna, 15 pengguna menjawab "Setuju" dan 5 pengguna menjawab "Sangat Setuju".

- Tingkat sistem mudah digunakan, 1 pengguna menjawab "Sangat Tidak Setuju", 2 pengguna menjawab "Tidak Setuju", 12 pengguna menjawab "Setuju" dan 5 pengguna menjawab "Sangat Setuju".

- Tingkat menerima informasi yang dibutuhkan tepat waktu, 1 pengguna menjawab "Sangat Tidak Setuju",16 pengguna menjawab "Setuju" dan 3 pengguna menjawab "Sangat Setuju".

- Tingkat sistem menyediakan informasi terbaru, 4 pengguna menjawab "Tidak Setuju", 14 pengguna menjawab "Setuju" dan 2 pengguna menjawab "Sangat Setuju".

\section{B. Saran}

Setelah dilakukan analisis dan hasil kuisioner maka dapat ditarik kesimpulan sebagai berikut:

- Website yang telah kami buat ini cukup memberikan informasi yang sesuai dengan kebutuhan pengunjung.

- Tepat waktu dalam memberikan informasi

- Akurasi sistem yg dibuat cukup memuaskan

\section{DAFTAR PUSTAKA}

[1] Arief, M.Rudianto.2011. Pemrograman web dinamis menggunakan PHP dan MySQL.Yogyakarta: Andi Offset

[2] Madcoms.2011. Membongkar Misteri Adobe Dreamwever CS6 denagn PHP dan Mysql.Yogyakarta: Andi Offset

[3] Prihatna, Hengky.2005. Kiat Praktis menjadi Webmaster Profesional. Jakarta: Elex Media Komputindo.

[4] Rosa dan Shalahunddin.2013.Rekayasa Perangkat Lunak.Bandung:Infotmatika Bandung:Citra Aditya Bangsa

[5] Sutanta, Edhy. 2011. Basis Data Dalam Tinjauan Konseptual. Yogyakarta : Andi Offse

[6] Wulandari,Lestari T.2013. Desain dan Perancangan Sistem Informasi Akademik Pada STMIK Ubudiyah Indonesia Banda Aceh. 